\title{
"Quero ter olhos pra ver a maldade desaparecer"! Fora, Bolsonaro! Impeachment, desde sempre e já!
}

O Sol há de brilhar mais uma vez A luz há de chegar aos corações Do mal será queimada a semente $O$ amor será eterno novamente É o juízo final A história do bem e do mal Quero ter olhos pra ver A maldade desaparecer

O Sol há de brilhar mais uma vez A luz há de chegar aos corações Do mal será queimada a semente $O$ amor será eterno novamente [...] (Composição de Élcio Soares, e Nelson Cavaquinho e Fernando Brant).

Começamos a escrever este editorial enfatizando o que normalmente fazemos no final dos editoriais: a esperança, a resistência política, a capacidade de resiliência e a luta dos professores de Educação Física, dos educadores e da classe trabalhadora em geral. A letra da música de Élcio Soares, Nelson Cavaquinho e Fernando Brant traz em seu bojo uma exaltação às utopias no lugar dessas distopias violentas, virulentas e destrutivas da vida: Bolsonaro, Covid-19 e necrocapitalismo. A bela letra da canção é um verdadeiro bálsamo para enfrentarmos a crise do capital e, consequentemente, a crise econômica e a calamidade sanitária que se abateu sobre o mundo. Agregue-se a isso tudo a calamidade mental que fez uma parcela de nós, brasileiros, lidar com a realidade plasmada pela capacidade predatória da vida, da política, da economia, da ciência, além da ignorância e dos negacionistas, dos terraplanistas e dos fascistas em geral. Não foi fácil. Dois mil e vinte foi um ano em que nossas práticas científicas e pedagógicas tiveram que ser adaptadas ao distanciamento social e à comunicação mediada pela tecnologia, entre outros aspectos. Por esse motivo, a epígrafe supracitada cai como uma luva, porque nos brinda com indicações objetivas e subjetivas de uma possível pauta de resistência para o enfrentamento do que está a caminho em 2021. Dessa forma, vamos prosseguindo com nossas peleias, tendo como lema os versos da música Juízo final, que nos incita a "queimar a semente do mal" e destruir o ovo da serpente à luz da "história do bem do mal", a "ter olhos pra ver a maldade desaparecer", assim como o ódio de classe, de gênero, de geração, de raça/etnia, dentre outras categorias ontológicas e políticas. 
Nesse limiar, é preciso seguir "caminhando de mãos dadas, com a alma nova" e "viver semeando a liberdade em cada coração", conforme a letra da música Credo, de Fernando Brant e Milton Nascimento. Com os versos de mais uma canção, queremos instigar nos leitores e leitoras, neste momento tão difícil, a motivação para, coletivamente, formularmos o iminente impeachment de Bolsonaro. Trata-se de derrotar o projeto do necrocapitalismo, que, para além da necropolítica, aponta para uma dinâmica em que o Estado escolhe quem morre ou "deixa de morrer", pois a morte é lucrativa para o capital. Isso significa que, muito além da necropolítica do nazifascismo, o necrocapitalismo expõe como a precarização do trabalho coloca em cena, cada vez mais, o trabalhador precarizado (ou uberizado), sujeito à insalubridade, à morte e à violência simbólico-real. Nesses termos, em situações de precarização, as vidas mais vulneráveis tornam-se mais curtas; e a morte, mais lucrativa. No contexto hiperneoliberal em que vivemos, as causas da pobreza são banalizadas e atribuídas às próprias vítimas. ${ }^{1}$ Nesse sentido, o projeto protofascista e capitalista de Bolsonaro se caracteriza pela convergência das estratégias da necropolítica com o necrocapitalismo. Em suma, somos duplamente atingidos por esses dois projetos genocidas. Subjaz a esses projetos a intenção deliberada de destruir o suposto excedente populacional pela via da disseminação do coronavírus.

As poéticas supramencionadas pretendem nos encher de coragem e compromisso éticopolítico, a fim de que enfrentemos o necroliberalismo, que enche nossos dias de ódio e pólvora, vindos desse vírus letal, que povoa nossos corpos e mentalidades, dias, tardes e noites. Essa poesia contida nas músicas parece sugerir, sabiamente, que utilizemos nossos escudos e saquemos nossas flechas cheias de indignação e esperança.

Diante da catástrofe do coronavírus, temos que entender que a conduta de Bolsonaro não é fruto de incompetência ou negligência, mas sim "uma estratégia institucional de propagação do vírus", conforme pesquisas realizadas pelas seguintes instituições: Centro de Pesquisas e Estudos de Direito Sanitário (Cepedisa), da Faculdade de Saúde Pública (FSP) da Universidade de São Paulo (USP), e a Conectas Direitos Humanos. Essas pesquisas revelam uma das mais macabras facetas da história da saúde pública no Brasil. ${ }^{2}$

Do ponto de vista global, numa breve síntese da conjuntura mundial, podemos dizer que a pandemia vem se mostrando o nosso principal problema, um desafio em escala planetária que ocupa nossas subjetividades e escancara a crise estrutural do capital, convertendo-se em crise sanitária, ambiental, econômica, política, educacional e cultural. São problemas que estão na ordem do dia, ladeados por problemas e questões éticas e estéticas, por concepções políticas e ideológicas. São grandes problemas que se convertem em desafios, advindos da simbiose entre a conjuntura mundial e a vida cotidiana universal e local. Problemas que, segundo Noam Chomsky e Vijay Prashad, ameaçam a longevidade da nossa espécie e do nosso planeta, em razão das "três maiores ameaças à vida na terra", a saber: a aniquilação nuclear, a catástrofe climática e a destruição neoliberal do

${ }^{1}$ FEREIRA, Wilson Roberto V. Necropolítica e Necrocapitalismo: editor do 'Cinegnose' duplamente marcado para

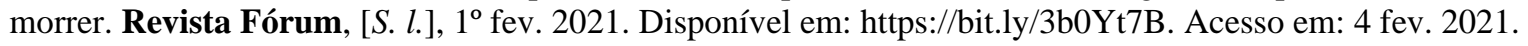

${ }^{2}$ BRUM, Eliane. Pesquisa revela que Bolsonaro executou uma "estratégia institucional de propagação do coronavírus". El País, [S. l.], 21 jan. 2021. Disponível em: https://bit.ly/2LzH6lu. Acesso em: 20 set. 2020. 
contrato social. Segundo os autores, para superar essas catástrofes, será preciso um internacionalismo robusto e unitário, capaz de despertar a atenção adequada e imediata para os perigos de extinção já mencionados: guerra nuclear, catástrofe climática e colapso social. ${ }^{3}$

Para nós, 2021 é um ano que carrega consigo sínteses parciais e globais em termos de pobreza política, que poderá trazer em seu bojo, implícita e explicitamente, uma enorme carga de atraso, mas também possibilidades de acirramento das contradições e, consequentemente, das possibilidades de luta e enfrentamento contra o necrocapitalismo bolsonariano, que teve seu apogeu golpista nas eleições presidenciais de 2018. Foi a partir do golpe de 2016 e das eleições de 2018 que a política brasileira passou a viver um verdadeiro caos. Vale lembrar que tudo começou com a participação de militares, milicianos e partidos antipetistas, sobretudo com a cumplicidade da mídia burguesa (Rede Globo de Televisão e seus conglomerados, entre outras instituições), que hoje se amarga com o próprio veneno que tomou: Bolsonaro expõe publicamente o ódio aos jornalistas da Rede Globo. Além disso, não se pode olvidar o apoio dos empresários e dos evangélicos neoliberais da 'teologia da prosperidade'.

Apesar de tudo, o ano 2021 poderá vir a desmascarar, de maneira exponencial, os golpes aplicados até o presente momento, como vêm fazendo o Intercept e outras mídias anticapitalistas. Nesse sentido, começa a aparecer, na produção científica, a construção obscura do golpe de 2016, caracterizado pelo impeachment da ex-presidenta Dilma e pela injusta e ilegal prisão de Lula antes das eleições de 2018, quando os militares deram um golpe branco pró-Bolsonaro e emparedaram o STF, para impedir a soltura e a candidatura de Lula. ${ }^{4}$ Além disso, estão amplamente divulgados os descaminhos e a farsa da Lava jato, ou melhor, da 'Vaza jato', que expôs a 'justiça' e os 'malfeitos ético-políticos' de Sérgio Moro e Dallagnol nos subterrâneos sombrios da republiqueta das bananas de Curitiba. Essa onda de golpes poderá seguir seu curso de forma dramática em nossa jovem democracia liberal.

Agora, em pleno mês de fevereiro, a ‘bola da vez' não é mais a consolidação do suposto 'golpe branco', mas a vitória do Centrão no Congresso, em conluio com Bolsonaro, como veremos adiante. O golpe branco, abortado por enquanto, tem como escopo a ideia, ainda não deflagrada oficialmente, de destituir o Congresso Nacional e, em seu lugar, instituir à força um Tribunal Militar. Ninguém tem sossego - é um golpe atrás do outro, uma destruição atrás da outra, uma morte atrás da outra. Está na hora de gritar: 'Basta! Fora, Bolsonaro!'. Como se vê, um outro golpe está pauta; o golpe da compra de parlamentares por Bolsonaro no processo de sucessão dos presidentes da Câmara dos Deputados e do Senado, para os quais foram direcionados bilhões de reais, no que chamamos de 'mercantilização da política'. Na verdade, Bolsonaro contraria uma de suas promessas de campanha: não repetir as práticas da 'velha política'. Pois bem, além de comprar os votos dos partidos de centrodireita com bilhões de reais em emendas parlamentares, Bolsonaro prometeu refundar alguns dos ministérios que viraram secretarias, a exemplo do Ministério do Esporte e do Ministério da Cultura, entre outros, descumprindo assim outra promessa de campanha.

${ }^{3}$ CHOMSKY, Noam; PRASHAD, Vijay Prashad. As três maiores ameaças à vida na terra. Carta Maior, [S. l.], 8 jan. 2021. Disponível em: https://bit.ly/36Uhbw2. Acesso em: $2^{\circ}$ jan. 2021.

${ }^{4}$ BARROCAL, André. Livro traz mais uma pista de 'golpe branco' pró-Bolsonaro na eleição. Carta Capital, [S. l.], 13 ago. 2019. Disponível em: https://bit.ly/3a137mv. Acesso em: 4 fev. 2021. 
Nesse emaranhado de promessas não cumpridas, compra de votos, negociatas de cargos estratégicos para a manutenção do poder, traições e uso indevido do dinheiro público, o que está em jogo mesmo é a blindagem do Congresso, visando à reeleição em 2022. Na verdade, o que Bolsonaro quer de fato é continuar seu projeto de poder protofascista e ditatorial, para evitar o impeachment, que, aliás, já poderia ter acontecido, se Rodrigo Maia, com sua 'ética na política', não tivesse, vergonhosa e lamentavelmente, engavetado os sessenta pedidos de impeachment protocolados até o dia final da sua gestão.

É com este fôlego que começamos 2021, ano decisivo, de um lado, pelo agravamento das destruições do Brasil e, de outro, pela intensificação das lutas e defesas das políticas públicas e sociais e do patrimônio público, tanto institucional quanto ambiental. É tempo de pandemias e pandemônios; ou melhor, tempo de "sindemia", conceito forjado por Merril Singer, conforme ressaltam os estudiosos da Fiocruz. Segundo eles, sindemia significa que a doença infeciosa não pode ser compreendida isoladamente, mas sim em articulação com fatores econômicos, distribuição de riqueza e acesso a bens essenciais, como moradia, saneamento, entre outros pontos da agenda social. Cabe destacar que o problema não é apenas a Covid-19, mas o próprio capitalismo sindêmico, que, de forma geral, prioriza a perversa lógica de acumulação privada da riqueza e das fortunas. ${ }^{5}$ Trata-se de um capitalismo cada vez mais desumano, regressivo, predador, concentrador de riqueza e difusor das desigualdades de classe. São tempos sombrios estes que vivemos no Brasil e no mundo, tendo como pano de fundo as agudas transformações do mundo do trabalho e sua consequente precarização, aliada à tragédia do coronavírus. Essa crise anticivilizatória e estrutural do capital se dá não apenas por meio da financeirização globalizada, mas também pelo brutal avanço tecnológico, cujos frutos são hegemonizados pelo grande capital privado, que lucra com a tragédia da Covid-19.

Nesse sentido, de acordo com Ricardo Antunes, o sistema sociometabólico do capital não tem limites para a sua expansão, convertendo-se numa processualidade incontrolável e profundamente destrutiva. ${ }^{6} \mathrm{E}$ isso pode ser constatado na ganância dos super-ricos brasileiros (bilionários, banqueiros, comerciantes e outros), que, durante a pandemia, aumentaram seus patrimônios em US\$ 34 bilhões. Segundo estudo da ONG Oxfam, entre 18 de março e 12 de julho de 2020, o patrimônio de 42 bilionários do Brasil passou de US\$123,1 bilhões para US\$ 157,1 bilhões. ${ }^{7}$ Isso certamente fará com que aumente a acumulação primitiva de capital, em meio ao acirramento das desigualdades de classe, cada vez mais abissais, que se materializam em desigualdades de renda, desigualdades educacionais, desigualdades laborais e outras.

5 'COVID-19 não é pandemia, mas sindemia': o que essa perspectiva científica muda no tratamento. Centros de Estudos Estratégicos da Fio Cruz, [S. l.], 14 out. 2020. Disponível em: https://bit.ly/3a5KXAl. Acesso em: 20 jan. 2021.

${ }^{6}$ ANTUNES, Ricardo. Introdução: substância da crise. In: MÉSZÁROS, István. A crise estrutural do capital. São Paulo: Boitempo, 2011. p. 11. SILVA, Maurício Roberto da. Editorial: O mundo do trabalho e os megaeventos esportivos e a crise estrutural do capital. Revista Motrivivência, Florianópolis, Ano XXIII, n. 36, p. 7-25, jun. 2011.

${ }^{7}$ PATRIMÔNIO dos super-ricos brasileiros cresce US\$ 34 bilhões durante a pandemia, diz Oxfam. G1, [S. l.], 27 jul. 2020. Disponível em: https://glo.bo/2LvxBUf. Acesso em: 20 jan. 2020. 
Em linhas gerais, desde que Bolsonaro tomou posse, em 2019, já vínhamos denunciando, de forma incisiva, as destruições e os desmontes das instituições e políticas públicas e sociais: a ciência \& tecnologia, a educação (em especial as universidades públicas). Tudo isso à base de cortes orçamentários, restrições de bolsas de estudo, congelamentos de salários, perdas de pessoal qualificado, fechamentos de unidades e encerramentos de pesquisas. É grande a lista dos estragos promovidos pelo governo de Jair Bolsonaro na Ciência, Tecnologia e Inovação nestes dois últimos anos. Por trás dessa destruição, impõe-se o núcleo econômico do (des)governo bolsonarista, que tem como escopo a privatização das universidades públicas e institutos federais, através do chamado capital educador, constituído pelos representantes dos bancos, das organizações financeiras e dos supostos setores modernos e internacionalizados, tendo como parceiros o agronegócio exportador e os atacadistas. ${ }^{8}$ Como se tudo isso não bastasse, vimos, paulatinamente, já pelo Future-se, o ataque às instituições e federais de educação superior, que culminou com a destruição da autonomia e, consequentemente, com a prática antidemocrática de intervenção no interior dessas instituições. O objetivo estratégico de interferência nas universidades, desde o início do governo de Bolsonaro, sempre foi corroer, à conta-gotas, a autonomia universitária. E tudo isso para converter as universidades em aparatos a serviço do governo e de seu projeto cultural e ideológico ultraneoliberal e protofascista. ${ }^{9}$ Para isso, vem autoritariamente manipulando a ordem de escolha dos reitores eleitos pela lista tríplice. Seu objetivo, supostamente, é não permitir, segundo ele, a escolha de reitores marxistas e de esquerda. De acordo com o Andes, ${ }^{10}$ são aproximadamente vinte instituições que estão sob intervenção do governo, quer pelo descumprimento inconstitucional da lista tríplice, quer seja pela indicação arbitrária de reitores: Universidade Federal do Vale do São Francisco (UNIVASF), Universidade da Integração Internacional da Lusofonia Afro-Brasileira (UNILAB), Universidade Federal da Fronteira Sul (UFFS), Universidade Federal da Grande Dourados (UFGD), Universidade Federal do Ceará (UFC),Universidade Federal do Espírito Santo (UFES), Universidade Federal do Recôncavo Baiano (UFRB), Universidade Federal do Semiárido (UFERSA),Universidade Federal do Triângulo Mineiro (UFTM), Universidade Federal dos Vales do Jequitinhonha e Mucuri (UFVJM), Universidade Federal do Rio Grande do Sul (UFRGS), Universidade Federal do Sul e Sudeste do Pará (UNIFESSPA), Universidade Federal da Paraíba (UFPB), Universidade Federal do Piauí (UFPI), Universidade Federal Sergipe (UFS), Instituto Federal de Santa Catarina (IFSC), Instituto Federal do Rio Grande do Norte (IFRN), Centro Federal de Educação Tecnológica do Rio de Janeiro (CEFET-RJ), Universidade Federal de Itajubá (UNIFEI) e Universidade Federal do Estado do Rio de Janeiro (UNIRIO).

Por outro lado, em contrapartida, a mobilização das entidades representativas do setor educacional consolidou um polo de luta contra a política bolsonarista e em defesa de décadas de avanços e conquistas. Esses movimentos de resistência estão diuturnamente na luta por instituições de ensino superior públicas, de qualidade e socialmente referenciadas. Esses sindicatos e movimentos

${ }^{8}$ LEHR, Roberto. Autoritarismo contra a universidade: o desafio de popularizar a defesa da educação pública. São Paulo: Expressão Popular, 2019.

${ }^{9}$ LEHR, Roberto. Guerra cultural e universidade pública: o future-se é a parte da estratégia de silenciamento. In: GIOLO, Jaime: LEHR, Roberto; SGUISSARD, Valdemar. Future-se: ataque à autonomia das instituições federais de Educação Superior e a sujeição do mercado. São Carlos: Diagrama, 2020. p. 107-149.

${ }^{10}$ CERCA de vinte instituições federais de ensino estão sob intervenção. Andes, Brasília, 21 jan. 2021. Disponível em: https://bit.ly/3a67Mns. Acesso em: 4 fev. 2021. 
sociais estão cientes da relevância pública, social e política, bem como do papel civilizatório e histórico que as universidades representam, para além do capital e da sujeição ao mercado.

Além de toda essa sanha predatória, destacam-se ainda a destruição das instituições públicas em geral, da previdência, dos direitos trabalhistas, da cultura e do meio ambiente, em especial a destruição da Amazônia e as tentativas de aniquilamento dos indígenas e quilombolas. Não menos dignas de nota são as ações que colocaram em risco a soberania nacional, como a entrega do nosso patrimônio e de nossas riquezas de forma subserviente ao imperialismo norte-americano de Trump (Pré-sal, Base de Alcântara, entre outras) e a privatização de setores estratégicos, a exemplo de aeroportos, portos, escolas, universidades, estradas e outras empresas e serviços importantes para a segurança nacional. Some-se a toda essa dimensão de terra arrasada as ameaças verbais aos seus supostos inimigos na política, a defesa da tortura e a volta do AI-5, vociferada por Bolsonaro, por militares e pelo rebanho de gados e admiradores fanáticos

Como se pode observar, as agruras e a perversão do governo Bolsonaro parecem não ter fim. Uma prova disso são nossos editoriais, sobretudo os do segundo semestre de 2020, dos quais advêm as ideias e reflexões acima aludidas. Passados mais ou menos três meses desde o último editorial, aqui estamos nós, estarrecidos, tendo que escrever sobre as novas/velhas destruições desse desgoverno. Há uma clara continuidade das maldades já consolidadas (queimadas da Amazônia e do Pantanal, solapamento dos direitos dos trabalhadores e reforma administrativa) e de outras que tomaram a cabeça lúgubre desse ser inominável. Trata-se de uma agenda que traz como pano de fundo o fogo do extermínio do meio ambiente, sob olhar destrutivo de Salles e, igualmente, o ódio nazifascista de Weintraub (ex-ministro da deseducação). Todos eles têm como método a transposição das estratégias e logísticas oriundas da caserna para as diversas instâncias da vida cotidiana civil (educação, trabalho, meio ambiente e outras). Agora, está em pauta a prática ultraneoliberal de uma economia de mercado, protagonizada pelo ministro Guedes, cuja defesa é a economia em primeiro lugar e, depois, se der, a vida dos trabalhadores e trabalhadoras infectados(as) ou no leito de morte.

Toda essa trama tétrica foi instaurada em articulação com o militar da ativa e ministro da saúde, Eduardo Pazuello, que, não obstante sua aclamada expertise logística, foi responsável pela falta de oxigênio no Amazonas, conforme ficou claro no caos protagonizado pelas Forças Armadas durante toda essa catástrofe humanitária. Para protagonizar esse caos no Amazonas, Pazuello não foi negligente nem incompetente. Ele apenas seguiu o plano que Bolsonaro e as Forças Armadas traçaram, baseando-se nas seguintes estratégias destrutivas, de acordo com pesquisas realizadas pelo Cepedisa/FSP/USP e pela Conectas Direitos Humanos: atos normativos da União, normas de autoridades ou órgãos federais e vetos presidenciais; atos de obstrução às respostas dos governos estaduais e municipais à pandemia; propaganda contra a saúde pública, definida como o discurso político que mobiliza argumentos econômicos, ideológicos e morais; além de notícias falsas e informações técnicas sem comprovação científica, com o propósito de desacreditar as autoridades sanitárias, enfraquecer a adesão popular a recomendações de saúde baseadas em evidências científicas e promover o ativismo político contra as medidas de saúde pública necessárias para conter o avanço da Covid-19. ${ }^{11}$

\footnotetext{
${ }^{11}$ BRUM, Eliane, 2021 (já citado).
} 
Durante a pandemia, os militares estão sendo associados ao uso da força para o silenciamento das consequências da miséria e do descaso. Eles não estão produzindo isso tudo por acaso, mas sim por descaso estratégico, com vistas a acirrar a miséria do nosso povo guerreiro, apesar de sofrido! O que eles vêm fazendo é consequência direta da maneira com que os militares sempre lidaram com a morte da sua própria população. Na verdade, longe de 'proteger', suas ações sempre se deram no sentido de lembrar aos setores vulneráveis da população brasileira o quão facilmente 'matáveis' eles são, em razão da força e das armas de que dispõem os militares, principalmente diante das determinações de classe, raça e gênero, como se vê cotidianamente nas favelas das grandes cidades. É em meio a essa perspectiva bélico-política e anticivilizatória que as Forças Armadas, como em 1964, vêm consolidando, antes e durante a pandemia, a sua relação orgânica e genocida com Bolsonaro. Nesse caso, 'juntou-se a fome com a vontade de comer' - ou, dizemos nós, 'com a vontade de matar'. Isso tudo faz parte da morte como crônica anunciada, haja vista a defesa da tortura, desde a ditadura de 1964 até os dias atuais, bem como o assassinato e a perseguição aos supostos inimigos políticos (comunistas, petistas e esquerdistas em geral). Some-se a isso as chacinas realizadas em bairros empobrecidos do Rio de Janeiro e de outras cidades brasileiras, nas quais um verdadeiro esquadrão da morte, composto por milicianos, exterminou mais de 400 pessoas, predominantemente crianças e jovens negros, espalhando o terror pelas comunidades.

É imperioso destacar, de acordo com Henri Bugalho, que a 'especialidade' de Bolsonaro é matar. Isso pode ser percebido na estética bélica e de morte, nas imagens dele simulando tiros com a 'arminha na mão' e no estímulo ao armamento da população. Além de toda essa violência, podemos evocar as inúmeras palavras ofensivas proferidas em seus discursos beligerantes, oriundas do esgoto, das quais emanam a violência, a segregação, o racismo, os estereótipos, o senso comum tosco e nazifascista, a homofobia e os preconceitos sociais contra determinados grupos. ${ }^{12}$ Essas condutas prestam um verdadeiro desserviço de deseducação para crianças e jovens. Para esses senhores deploráveis, a política é uma guerra, uma luta de vida ou morte, na qual apenas um pode sobreviver; a política de guerra, enquanto necropolítica e necroliberalismo, inviabiliza e destrói as pequenas e grandes convivências democráticas. ${ }^{13}$ No entanto, todo esse quadro, que expõe as mazelas desse tipo de antipolítica, é introjetado no chamado 'brasileiro médio', sem consciência crítica ou política. Esse tipo de gente fanática ostenta orgulhosamente o 'Jair que há em si', em especial os nauseabundos que endeusam a hierarquia, condenam a homossexualidade e amam a autoridade e a família patriarcal. Além disso, essa canalha fanatizada vê mulheres, negros e índios como seres inferiores e menos capazes, tem nojo de pobre e ódio de classe, embora seja incapaz de perceber que é tão pobre quanto os que condena e abomina. $\mathrm{O}$ brasileiro médio, cúmplice do projeto exterminador e genocida de Bolsonaro, acredita que a pobreza e o desemprego estrutural são consequências da falta de fibra moral e de empenho individual por parte dos trabalhadores, não percebe que a própria miséria e a falta de dinheiro não são culpa dos trabalhadores e trabalhadoras empobrecidos(as), mas sim uma idiossincrasia do capitalismo ultraneoliberal.

Desse conluio macabro entre o (des)governo e as Forças Armadas exsurge, desde sempre, a defesa da economia política capitalista, em detrimento do salvamento de vidas humanas. Nesse mesmo pacote cabe o recrudescimento da negação da ciência, que culminou com o plano de não

${ }^{12}$ BUGALHO, Henri. Minha especificidade é matar: como o bolsonarismo tomou conta do Brasil. Curitiba: Kotter, 2020. p. 11-12.

${ }^{13}$ NOBRE, Marcos. Ponto Final: a guerra de Bolsonaro contra a democracia. São Paulo: Todavia, 2020, p. 10. 
comprar vacinas em tempo nem providenciar oxigênio para as vítimas de Manaus. Uma prova disso é que foi o Amazonas o estado em que houve mais mortes por asfixia, por causa da negligência obstinada de Bolsonaro e Pazuello, que aproveitaram o ensejo para, numa sanha negacionista, divulgar fake news sobre o uso da Cloroquina, enquanto as pessoas não podiam respirar por falta de oxigênio e morriam. Morriam como morreram, há alguns meses, animais e árvores centenárias no 'pulmão do mundo', a Amazônia.

Há, nesse sentido, claramente, uma negligência planejada, cuja intenção é 'deixar com que morram' pobres, negros, indígenas, velhos e velhas, aproveitando a pandemia para descartar os 'indesejáveis'. Sendo assim, movido pelo negacionismo obscurantista da ciência, Bolsonaro e os militares, de forma violenta e autoritária, impõem a setores da população uma relação dramática e alienada entre ciência, política e saúde. O negacionismo da ciência se dá, fundamentalmente, em razão das fragilidades na educação científica e política da população brasileira, bem como das disputas político-partidárias entre diferentes níveis hierárquicos do governo. Em vista disso, as consequências do negacionismo da relevância da ciência se configuram, fundamentalmente, como retrocessos em termos de emergência sanitária e desprezo pelos direitos à saúde e à vida.

Considerando tudo o que já foi mencionado, continuamos com a opinião de que Bolsonaro deve sofrer impeachment, levando em conta suas condutas e omissões na pandemia e demais motivos já aludidos. Por isso, bradamos 'Impeachment, já!'. São suficientes, para tanto, as inúmeras improbidades no exercício do cargo, além dos crimes de responsabilidade - na verdade, crimes de lesa-pátria e lesa-humanidade - cometidos contra as instituições, contra a democracia e contra a vida de mais de 200 mil pessoas que pereceram e de outas tantas que foram contaminadas pela Covid-19. Há, portanto, inúmeros motivos para o seu afastamento, pois ele deveria ter seguido as recomendações científicas para conter a doença no lugar de fazer vistas grossas à tragédia, ridicularizar os mortos $\mathrm{e}$ estimular o desprezo pela vida. Esperava-se desse genocida que coordenasse e planejasse as políticas sanitárias e de saúde cuja responsabilidade é da União. Também se esperava que fortalecesse o SUS, melhorando a gestão de leitos de UTIs e garantindo assim o isolamento social e a realização testes em massa; que se empenhasse na busca e no financiamento da vacina em tempo hábil e, por fim, que assegurasse o auxílio emergencial para o enfrentamento deste período difícil, durante todo o tempo em que a população brasileira estivesse sob riscos de contaminação e morte pelo coronavírus. ${ }^{14}$

Diante de tanto descaso e maldade, que levaram a mais de 200 mil mortos, reiteramos: 'Fora, Bolsonaro!', 'Impeachment, já!'. Por ter atentado contra os direitos e os princípios constitucionais mais primários: o direito à vida e à saúde. Ademais, quando se observa a dimensão jurídica, sobram razões para seu impeachment. Outrossim, também na dimensão política, como já foi mencionado, cabe ao Parlamento brasileiro investigar a conduta presidencial e acatar os mais de sessenta pedidos de impeachment. 
As Forças Armadas também devem ser responsabilizadas por sua associação com o governo Bolsonaro, especialmente durante a pandemia, visto que os militares ajudaram a produzir essa catástrofe humanitária, além de não medirem esforços para garantir a manutenção de Bolsonaro no poder, entre ameaças de golpe e uso da força. Em vista disso, a única saída é o impeachment. Tenhamos plano de saúde ou não, incumbe-nos o dever de fazer protestos de rua pela saída do presidente, pois só a força e a mobilização populares poderão fazer as Forças Armadas ocuparem seu único e verdadeiro lugar: de volta aos quartéis, longe da vida política nacional. ${ }^{15}$

Em meio à pandemia, Bolsonaro traça a sua proposta de gastos com as Forças Armadas. O orçamento de 2021 prevê um aumento de $\mathrm{R} \$ 110,7$ bilhões nas despesas primárias do Ministério da Defesa, alta de 4,7\% em relação a 2020 (R \$ 105,7 bilhões). Esses gastos bilionários devem levar a cortes em outras políticas públicas e sociais, a exemplo da saúde e da educação. A pergunta que se impõe é: por que a Defesa ganhou aumento maior que a Educação e a Saúde na proposta de orçamento? A resposta objetiva é: em razão do coronavírus, houve um rompimento do Teto de Gastos para 2021, autorizado pelo Congresso. Então, aproveitando-se disso, o (des)governo propõe o aumento do orçamento das Forças Armadas acima da inflação e uma previsão de crescimento menor ou mesmo cortes em outras áreas. Nesse sentido, por exemplo, o aumento previsto para a Defesa supera a alta do orçamento proposto para o Ministério da Educação - elevação da despesa primária em $\mathrm{R} \$ 2,4$ bilhões, uma alta de apenas $2 \%$ em relação ao proposto para este ano -, ao passo que, para os gastos da Saúde, está prevista a quantia de R \$ 135 bilhões em 2021, uma pequena elevação (1,7\%) em relação ao que o governo propôs no ano passado ( $\mathrm{R}$ \$ 132,8 bilhões), mas uma redução drástica ante o orçamento atual da pasta para este ano (R $\$ 173,4$ bilhões), que foi substancialmente elevado pelos gastos emergenciais para conter a pandemia de coronavírus. ${ }^{16} \mathrm{O}$ mesmo aconteceu com o Meio Ambiente (queda de 4,7\%, orçamento atual de R \$ 2,1 bilhões), a Agricultura (redução de 1,7\%, orçamento de R \$ 14,4 bilhões) e o Desenvolvimento Regional (menos 6\%, orçamento de R\$ 8,9 bilhões). Além disso, o Ministério de Ciência \& Tecnologia teve uma redução drástica de $25 \%$ (orçamento de $\mathrm{R} \$ 5,2$ bilhões), que, em parte, deve-se ao seu desmembramento para recriação do Ministério das Comunicações (orçamento de R \$ 2,7 bilhões), órgão que recebeu também recursos que eram da Presidência da República (redução de 63\%, orçamento de R \$1,6 bilhão).

Diante dessas contradições, no entanto, Bolsonaro, ainda no mês de dezembro, reiterando seu negacionismo da ciência no combate ao coronavírus e recusando-se a dar continuidade ao Auxílio Emergencial e a comprar vacinas, vociferou que o Estado está quebrado e, por essa razão, não consegue resolver a situação: não posso fazer nada, disse o chefe do Executivo da $12^{\mathrm{a}}$ economia do planeta. ${ }^{17} \mathrm{Em}$ seu favor, argumentou que a culpa dessa crise é da pandemia e da mídia, enquanto tripudiava sobre o número de mortos e infectados pela Covid-19. Não obstante, deu bilhões aos bancos, gastou milhões em compras de leite condensado, cerveja e churrasco para consumo da presidência e dos militares. Por fim, ocupou mais da metade dos cargos dos ministérios com militares, elevou os salários dos militares como forma de compensar a reforma da previdência militar, perdoou

${ }^{15}$ SAFATLE, Vladimir. As Forças Armadas do caos. El País, [S. l.], 26 jan. 2021. Disponível em: https://bit.ly/36SWKjc. Acesso em: 20 jan. 2021.

${ }^{16}$ SCHREIBER, Mariana. Os gastos bilionários que Bolsonaro propõe para a Defesa e que levarão a cortes em outras áreas em 2021 em outras áreas. BBC, [S. l.], 21 ago. 2020. Disponível em: https://bbc.in/3qcbIIV. Acesso em: 20 set. 2020.

${ }^{17}$ O BRASIL está quebrado e eu não posso fazer nada, diz Bolsonaro. O tempo, [S. 1.], 5 jan. 2021. Disponível em: https://bit.ly/3rMz34m. Acesso em: 20 set. 2020. 
1 bilhão de impostos das igrejas evangélicas, acenou para a compra de armamentos e caças de guerra e concedeu bilhões em emendas para a compra dos parlamentares do Centrão nas eleições para o Congresso.

Como se não bastasse o rol de atrocidade que descrevemos, antes do fechamento deste editorial foi eleita a dupla do inominável Centrão, comprado por Bolsonaro, Arthur Lira (Câmara) e Rodrigo Pacheco (Senado), com objetivo de continuar com a pauta hiperconservadora e livrar o chefe da gangue de um impeachment. Foram bilhões de reais desviados do erário público para financiar as bancadas, por meio de projetos e emendas parlamentares, dinheiro este que poderia ser melhor aplicado na compra ou fabricação de vacinas e insumos. Esse novo golpe põe em risco a já combalida democracia brasileira, tanto no que tange à pauta da política econômica ultraconservadora (reformas administrativa e tributária, ampliação do projeto de Transferência de Renda, Nova Lei do Gás, aceleração da privatização das estatais - sonho de Guedes -, flexibilização do porte de armas, direitos dos entregadores, entre outros pontos da agenda política, econômica e social) ${ }^{18}$ quanto no que concerne à pauta de costumes (racismo, homofobia, feminicídio). Vale lembrar que o Centrão é um bloco da antipolítica, em cujo cerne se encontram políticos condenados por inúmeros crimes de responsabilidade, verdadeiras aves de rapina da velha política e do fisiologismo, que visam lucrar com a política, independentemente de ideologias e do interesse público. ${ }^{19}$

À guisa de síntese, podemos dizer que começamos o ano numa situação de agravamento das crises e emergências sanitárias, econômicas, políticas e educacionais, que desde a posse de Bolsonaro vêm destruindo vidas, habitações, comunidades, plantações e rios. Durante todo seu mandato, mas sobretudo durante a pandemia, Bolsonaro aproveitou para vetar direitos, dar aumento aos militares e entregar o país para a iniciativa privada (nacional e internacional), abrindo assim as 'porteiras' da exclusão social, negando o direito à saúde, ao trabalho e à educação aos(às) trabalhadores(as) mais pobres e vulneráveis. Mas a história da pandemia deverá punir também Rodrigo Maia, que, com o seu neoliberalismo tão perverso quanto o de Bolsonaro e Guedes, foi fraco, covarde e subserviente; e o mesmo se pode dizer do STF, muitas vezes omisso, medroso e leniente, assim como da PGR, que se fez de surda o tempo inteiro.

Em suma, 2021 é um ano-chave e emblemático para o Brasil, uma vez que as primeiras semanas de janeiro já apontaram o que vem por aí em termos de política: as possibilidades de novos golpes e destruições das políticas públicas e sociais, sob a batuta das Forças Armadas e de Bolsonaro, no colo do Centrão, aumentando a desigualdade de classe e garantindo a acumulação no âmbito da ditadura do capital. Dois mil e vinte um ficou marcado como o ano do caos em Manaus, do descaso para com a preservação da vida de milhões de brasileiros e brasileiras; da escassez de vacina e insumos para o combate ao coronavírus; do acirramento das desigualdades sociais e regionais; do subemprego (uberização do trabalho) e do desemprego estrutural; das novas variantes do coronavírus

${ }^{18}$ OHANA, Victor. 10 temas que devem entrar em votação no Congresso Nacional em 2021. Carta Capital, [S. l.], 6 jan. 2021. Disponível em: https://bit.ly/3q3YDkz. Acesso em: 20 jan. 2021.

${ }^{19}$ LAGO, Ivann. O Jair que há em nós. Racismo Ambiental, [S. l.], 3 dez. 2020. Disponível em: https://bit.ly/3cSHR4d. Aceso em: 20 jan. 2021. 
que se espalham pelo Brasil; das eleições no Senado e na Câmara, que revelaram a pobreza política em que estamos imersos, entre outras problemáticas que surgem e se agravam dia após dia.

Vivemos, de um lado, uma conjuntura eivada de momentos críticos e marcada pelo projeto necrocapitalista; e, de outro, a luta dos contrários, um enorme e inegociável potencial acumulado de resistência e resiliência por parte dos movimentos sociais e sindicais diante destes desafios hercúleos: recessão, desemprego, fome e pandemia. Nessa perspectiva, apesar do Centrão, os temas que compõem a conjuntura nacional para 2021 devem contemplar a seguinte pauta no âmbito das políticas públicas: ausência de uma política clara e precisa de vacinação para todos os trabalhadores e trabalhadoras, em razão do negacionismo da ciência e da politização da vacina entre Bolsonaro e Dória, fato gravíssimo, que afronta a ciência e põe vidas em risco, agravando potencialmente o número de mortos e infectados; a democratização da vacina 'para todos', em face da desigualdade global na distribuição da vacina pelos países mais ricos e as empresas farmacêuticas, fato este que fará com que nove entre dez pessoas de alguns dos países mais pobres do mundo fiquem sem a vacina em 2021 ${ }^{20}$ a preservação e ampliação do SUS; a privatização das estatais; as reformas tributária e administrativa; o trabalho precarizado e a uberização do trabalho; a transferência de renda; a extensão do auxílio emergencial para os desempregados, subempregados e trabalhadores de baixa renda; a taxação das fortunas dos mais ricos; o aumento dos impostos dos mais ricos; a luta pela autonomia universitária e contra a intervenção antidemocrática na eleição dos reitores das universidade federais; as lutas contra o racismo estrutural, a misoginia, o feminicídio (sobretudo de mulheres negras) e a transfobia; o ambientalismo sistêmico e estrutural; a demarcação das terras indígenas; entre outros pontos da agenda política, econômica e social.

Com relação à Educação Física, pensamos que a pauta oriunda da conjuntura mais genérica, tanto global quanto brasileira, poderá, de alguma forma, respingar na cultura corporal em movimento na área. Do ponto de vista das especificidades, há muitos desafios, uns antigos e outros mais atuais, que devem articular-se com os desafios mais globais, como nos lembraram Noam Chomsky e Vijay Prashad no início do editorial: problemas que ameaçam a longevidade da nossa espécie e do nosso planeta.

O desafio na pauta das especificidades é seguir acompanhando as lutas coletivas engendradas pelo Colégio Brasileiro de Ciências do Esporte (CBCE), através de seus GTTs e grupos de pesquisa. Nesses termos, urge fazer análises de conjuntura mais globais, porém sem perder de vista a potência, as especificidades e as problemáticas teórico-conceituais, teórico-práticas e político-pedagógicos da Educação Física. Esse procedimento pode ser materializado em nossas pesquisas, aulas, encontros, lives e outros eventos. Além disso, cumpre desenvolver pesquisas sobre a Educação Física e seu papel em tempos de Covid-19 e continuar a luta teórico-metodológica e ideológica contra o projeto Bolsonarista no interior do Confef. 
Do ponto de vista editorial, vale lembrar que, com a transição para o modelo de publicação contínua, iniciada no segundo semestre do ano passado, essa é a primeira edição anual da Motrivivência no novo sistema. Para inaugurar essa edição, foram selecionados onze (11) textos remanescentes de 2020, cuja aprovação, já ao final do ano, não possibilitou que fossem publicados ainda naquele ano. A eles, irão se somar, ao longo de 2021, novos textos à medida que vierem a ser aprovados.

A capa da presente edição é uma contribuição generosa do professor e fotógrafo Ronaldo Andrade à Motrivivência. Ela expressa um flagrante da tradicional pesca da tainha, que ocorre nos meses de inverno na praia do Campeche, em Florianópolis/SC. A foto foi tirada em julho de 2020 e expressa o cuidado cidadão dos pescadores que, mesmo numa atividade ao ar livre, fazem uso das suas máscaras sanitárias. Ronaldo Andrade, junto com a também fotógrafa Mara Freire, produz o Calendário do Campeche, verdadeira obra de arte da fotografia, com imagens que tematizam os espaços e as atividades típicas daquele balneário da Ilha de Santa Catarina - o mesmo que, há cerca de um século, foi objeto do olhar atento do escritor Antoine de Sant-Exupéry, então piloto do Correio Aéreo, que tinha o Campeche como ponto de apoio para as linhas entre o Rio de Janeiro e Buenos Aires, na Argentina.

Em nossa seção de Homenagens, reverenciamos os profissionais que trabalham nos diversos campos ligados à saúde, e que tem atuado, já há cerca de um ano, no enfrentamento da pandemia causada pelo novo coronavírus. Simbolicamente, nossa Homenagem destaca a sra. Maria Aparecida Alves dos Santos, enfermeira da Prefeitura Municipal de Corumbá/MS, que no ato da sua vacinação expressou seu protesto silencioso, porém muito eloquente, mostrando sua disposição e coragem para enfrentar o vírus e o verme!

Por tudo isso, expressamos nossos cumprimentos e agradecimentos a estes verdadeiros heróis e heroínas da luta cotidiana contra a COVID-19.

Todo esse caos político, econômico, sanitário e social exige unidade de luta para além do capital; exige atitudes coletivas em prol da superação do reino da necessidade e em direção ao reino da liberdade; exige de todos nós uma postura calcada na máxima gramsciana, tantas vezes citadas, mas difícil de ser colocada em prática: "ser pessimista na análise e otimista na ação". Ademais, ter força, fé, gana e luta: “Tenha fé no nosso povo, que ele resiste, tenha fé no nosso povo, que ele insiste [...]. Tenha fé no nosso povo, que ele acorda, tenha fé no nosso povo, que ele assusta". ${ }^{21}$ Nessa mesma linha de reflexão, é preciso encarar o desafio de "estar no fundo do poço e continuar cavando". ${ }^{22}$ Mais ainda, de estar num túnel escuro e ser capaz de encontrar frestas de luz, em meio à escuridão, que possam indicar, para o futuro do presente, a superação das distopias e novos desafios, utopias e caminhos rumo à emancipação da classe trabalhadora, explorada e aviltada pela avidez da acumulação ensandecida de capital.

${ }^{21}$ Trecho da música Credo, de Fernando Brant e Milton Nascimento.

${ }^{22}$ HALIMI, Serge. Chegar ao fundo do poço... e continuar cavando. Le Monde Diplomatique, São Paulo, Ano 12, n. 140, p. 2, mar. 2019. Disponível em: https://bit.ly/3cZysoN. Acesso em: 20 maio 2020. 
O importante em todo esse movimento de resistência ativa é criar focos de civilização em meio à barbárie. Para isso, é de suma importância usar a imaginação para inventar e reinventar caminhos, possibilidades e estratégias de enfrentamento, veladas e explícitas, a fim de enfrentar os idólatras do mal autorizados por Bolsonaro. ${ }^{23} \mathrm{~A}$ imaginação, neste caso, deve ser canalizada para a superação do protofascismo deflagrado na política brasileira e a busca da liberdade dos pontos de vista de classe, raça/etnia, gênero, geração e cultura, pois, afinal, pensando nas desigualdades raciais e de classe, Angela Davis nos lembra de que a liberdade é uma luta constante. ${ }^{24}$ Referimo-nos à construção de projetos individuais e coletivos que tenham como mote a inseparabilidade entre política, arte e ciência.

Para encerrar, deixamos um desafio superador não só para 2021 mas também para daqui em adiante; um naco de esperança, uma ação crítica e transformadora, a partir de fragmentos do poema No te rendas, do poeta uruguaio Mário Benedetti: "Não te rendas que a vida é isto: continuar a viagem, perseguir os teus sonhos, destravar os tempos, arrumar os escombros e destapar o céu. Não te rendas, por favor, não cedas, ainda que o frio queime, ainda que o medo morda, ainda que o sol se esconda, e se cale o vento: ainda há fogo na tua alma, ainda existe vida nos teus sonhos." "Non te entregues, corazón libre". ${ }^{25}$

Fora, Bolsonaro! Impeachment, desde sempre e já! Abaixo o Centrão! Pela autonomia universitária! Não à intervenção nas universidades e nos institutos federais de ensino superior! Vacina para todos os trabalhadores e trabalhadoras do Brasil e do mundo!

Desejamos uma leitura crítica e propositiva.

Floripa, fevereiro de 2021.

Os editores

Maurício Roberto da Silva, Giovani De Lorenzi Pires, Rogério Santos Pereira

${ }^{23}$ KEHL, Maria Rita. É preciso criar focos de civilização em meio à barbárie. www.brasildefato.com.br

${ }^{24}$ DAVIS, Angela. A liberdade é uma luta constante. São Paulo: Boitempo, 2018.

${ }^{25}$ Trecho da música Corazón Libre, de Mercedes Sosa. 